\title{
CASO EMPRESARIAL
}

\author{
BUSINESS CASE
}

\section{Be Cordial Hotels \& Resorts, una apuesta de un grupo de emprendedores por la expansión en el mercado turístico y por la sostenibilidad}

\author{
Yasmina Araujo-Cabrera, Teresa Aguiar-Quintana ${ }^{1}$ \\ Universidad de Las Palmas de Gran Canaria (ULPGC), España
}

doi: 10.20420/eni.2019.245

\begin{abstract}
Resumen
Be Cordial Hotels \& Resorts es una cadena hotelera que comenzó su actividad en enero de 2004 en la isla de Gran Canaria (Archipiélago Canario, España), y que actualmente gestiona íntegramente más de 1.735 unidades alojativas además de 214 unidades alojativas en gestión comercial. Con todo ello el número de unidades comercializadas se eleva a 1.949 que, en el ejercicio 2017, aportaron una facturación neta consolidada de 60 millones de euros. A finales de 2018 el Grupo gestiona 12 establecimientos en Gran Canaria y Lanzarote y gestiona comercialmente un hotel en República Dominicana, la primera incursión internacional de una cadena con vocación de expandirse de forma sosegada e imparable. Los inicios de esta empresa hotelera están marcados por la colaboración y el entendimiento de muchos emprendedores canarios del ramo de automoción y alimentación que aportaron el sentido de profesionalidad y cordialidad que impregna el espíritu de esta empresa desde los años 80. Su apuesta por la expansión y la diferenciación, han llevado a la empresa a consolidar una importante posición en el mercado turístico canario. La empresa, además, ha estado guiada por una filosofía de gestión basada en la sostenibilidad medioambiental, el trato amable y cordial a sus huéspedes, así como su compromiso con el entorno social, histórico y cultural, valores que le han permitido lograr la certificación "Oro" de Travelife (organización de reconocimiento europeo en auditoría de turismo sostenible).
\end{abstract}

Palabras clave: emprendimiento, marca, gestión, sostenibilidad, estrategia.

Clasificación JEL: M140, M160.

Fuente de referencia: Araujo-Cabrera, Y.; Aguiar-Quintana, T. (2015). Cordial Canarias: amabilidad y sostenibilidad, claves de la cultura organizativa. En Aguiar-Quintana, T. y Batista-Canino, R.M. (Eds.). Casos de éxito turístico en Canarias (pp. 213-219). Editorial Síntesis: Madrid.

\section{Orígenes del grupo empresarial}

A finales de los 80 un grupo de empresarios del ramo de la automoción y del sector industrial de la alimentación y bebida con figuras tan destacadas como D. Antonio Vega (cerveza Tropical); D. Domingo González (Agua de Firgas); D. Lizardo Martell (Vidrieras Canarias, Pepsi-Schweppes); D. José Sánchez (JSP); D. Andrés Megías (Pastas la Isleña); D. Juergen Flick; y otros empresarios que gestionaban empresas como Arehucas, Tirma o Kalise, adquieren dos complejos de bungalows en el Campo Internacional de Maspalomas (Green Golf y Sandy Golf). A este proyecto se adhirió D. Nicolás Villalobos de Paiz quien a su vez incorporó el complejo de Bungalows Biarritz en Playa del Inglés, establecimiento que venía gestionando desde los años 70 cuando su grupo familiar adquirió una participación significativa en el mismo.

19Autor de correspondencia: teresa.aguiar@ulpgc.es 
Así, en sus inicios el Grupo Turístico sumaba 470 unidades alojativas de carácter extrahotelero, tamaño insuficiente para afrontar el costoso lanzamiento comercial de una marca que adquiriera notoriedad en los mercados emisores. Para salvar esta limitación, se lidera la conformación a comienzos de los años 90 de una Agrupación de Interés Económico junto a otros hoteleros independientes para compartir la marca comercial Amigos HBA. A finales de los 90 la marca aglutinaba a más de 2.000 unidades alojativas y gozaba de una enorme notoriedad en importantes mercados emisores como el alemán. Sin embargo, a comienzos del siglo XXI la gestión de la marca se hace inmanejable ante la imposibilidad de pactar entre grupos turísticos independientes políticas comunes de comercialización. Finalmente, en el año 2003, los socios que conformaban el grupo Amigos HBA se separan y liquidan la Agrupación de Interés Económico.

En estos mismos años, el grupo incorpora a nuevos socios estratégico como D. Sergio Alonso (empresa Domingo Alonso) y decide embarcarse en un proyecto de dimensiones extraordinarias en el Puerto de Mogán que abarcaba al Hotel Cordial Mogán Playa, inaugurado en diciembre de 2004, así como al complejo de apartamentos Cordial Mogán Valle, inaugurado en junio de 2008. La masa crítica que aportaba este proyecto en el Puerto de Mogán permitió la conformación a comienzos del año 2004 de una estructura de cadena hotelera bajo una nueva marca, Cordial Canarias Hotels \& Resorts.

El éxito del proyecto ha seguido atrayendo a inversores destacados y notorios como es el caso del célebre futbolista grancanario David Jiménez Silva quien a finales del año 2013 adquirió una relevante participación accionarial.
2 Presente y futuro de la compañía be CORDIAL HOTELS \& RESORTS que apuesta por la calidad de servicio a través de inversión en hoteles propios y por el crecimiento basado en su estrategia de contratos de gestión integral y de gestión comercial

La elección de la marca ha sido uno de los grandes aciertos de este grupo. Basándose en la marca anterior que adoptó el grupo de empresarios promotores de Amigos HBA, la marca Be Cordial va más allá pues representa cordialidad que procede del latín cordis, cuyo significado etimológico es corazón, que era justo lo que pretendía transmitir este grupo según $\mathrm{D}$. Nicolás Villalobos Mestres (Director General del Grupo be Cordial): "el compromiso, de corazón, con el bienestar de sus huéspedes”. Este lema ha sido el leitmotiv de la empresa.

El grupo Cordial engloba establecimientos de una, dos, tres y cuatro estrellas que, a pesar de poseer diferente categoría como alojamientos turísticos, muestran todos como denominador común características como la cordialidad y la orientación a la satisfacción del cliente. A este respecto, el principal objetivo del grupo es garantizar a sus huéspedes el descanso en un entorno respetuoso y amigable, y esto se traduce en una esmerada y amable atención y en un programa de mejoras continuas en sus establecimientos para garantizar la calidad. Esta filosofía ha impregnado y fluido en toda la organización $\mathrm{y}$ ha permitido que los establecimientos hoteleros y extrahoteleros que conforman el Grupo hayan acumulado, año tras año, numerosos premios en reconocimiento a la elevada satisfacción de sus huéspedes. En consecuencia, puede decirse que el grupo Be Cordial posee una cultura organizativa fuerte, puesto que los valores centrales de la empresa son compartidos con gran intensidad y de forma extensa por toda su plantilla (Sorensen 2002).

Con la apertura del Hotel Cordial Mogán Playa, en diciembre del año 2004, el Grupo Cordial entró en una encrucijada ya que, por un 
lado, acababan de inaugurar un hotel llamado a ser referente en las Islas y, por otro, tenían tres establecimientos extrahoteleros de los años setenta y ochenta que, a pesar de haber hecho un gran esfuerzo en su conservación a través de la reinversión constante en la mejora de sus instalaciones, inevitablemente comenzaban a sufrir de una cierta obsolescencia. Es por ello que, en el año 2006, deciden acometer una fuerte inversión sin ningún tipo de ayuda ni de incentivo público, para lograr que cada establecimiento, en su respectiva categoría, se convirtiera en un referente de calidad, logrando así una cierta armonía entre todos ellos. Con este objetivo, el grupo invirtió una cantidad aproximada de 15 millones de euros para el proceso de reconversión de la planta, en torno a los 30.000 euros en cada unidad alojativa. Todo ello, unido a los más de 75 millones de euros invertidos en el Hotel Cordial Mogán Playa, y a los 45 millones de euros en los apartamentos Cordial Mogán Valle, lo que supuso para el grupo una inversión total de aproximadamente 135 millones de euros.

La fuerte inversión realizada motivó que la ulterior expansión del grupo se acometiera no a través de inversión de recursos financieros (promoción de obra nueva o compra de activos existentes) o de asunción de riesgos financieros (alquileres), sino a través de contratos de gestión integral o comercial de establecimientos explotados por terceros.

Estos contratos de gestión que han desarrollado fueron posibles gracias a la existencia de una estructura interna fuerte y consolidada y un rico know-how fruto de la dilatada trayectoria del Grupo en la gestión de establecimientos turísticos. De este modo, el grupo apostó por dos tipos de contratos: contratos de gestión integral y contratos de gestión comercial. En los contratos de gestión integral, el Grupo Cordial asumía la dirección técnica de comercialización, administración y control de la explotación turística en sus diferentes vertientes por cuenta de la titular de la explotación que, por este contrato, delega la gerencia del mismo.

Con esta nueva fórmula de gestión integral, en septiembre de 2010 el Grupo Cordial Canarias asumió la gestión del Hotel Cordial Golf Plaza, establecimiento con 174 unidades alojativas de categoría 4 estrellas, ubicado en el Sur de Tenerife. Posteriormente, en noviembre de 2011, incorporaría bajo esta misma modalidad de gestión, el Best Age Fuerteventura, un hotel cuatro estrellas ubicado en Costa Calma (isla de Fuerteventura, Archipiélago Canario). La gestión integral del Grupo Cordial sirvió para restructurar la operación turística de ambos establecimientos, circunstancia que aprovecharon las respectivas propiedades para vender los hoteles a finales del 2015 lo que supuso la desafiliación del Grupo Cordial de los mismos de forma ordenada durante el primer semestre del 2016.

A comienzos del año 2017, el Grupo Cordial asume la gestión integral del Hotel \& Spa Cordial Roca Negra, un hotel de cuatro estrellas de 88 habitaciones en Agaete (isla de Gran Canaria), y a finales del mismo año incorpora con el mismo modelo de gestión el Aparthotel Rubimar Suites de cuatro estrellas con un total de 96 habitaciones en la isla de Lanzarote, un paso más en su estrategia de expansión orientada a la búsqueda permanente de destinos atractivos que proporcionen experiencias vacacionales de calidad a sus huéspedes. Posteriormente, en enero del 2018, el Resort Marina Élite, de 265 apartamentos, pasa de estar en el modelo de gestión comercial a adoptar el modelo de gestión integral. En marzo del mismo año se inaugura Cordial Muelle Viejo, con 22 viviendas vacacionales en gestión integral.

Además, recientemente, el Grupo ha firmado nuevos contratos en gestión integral (ej. Paraiso, Solás y Galdós), entre ellos con un hotel boutique urbano de 28 habitaciones (Hotel Cordial Triana) 
que espera abrir sus puertas a comienzos del año 2019 tras la reforma de un espectacular palacio modernista ubicado en el barrio de Triana de la ciudad de Las Palmas de Gran Canaria (isla de Gran Canaria). También se encuentran con un gran proyecto en curso en la zona de Arguineguín con tres parcelas de viviendas vacacionales de más de 80 unidades alojativas.

En cuanto a los contratos de gestión comercial, Grupo Cordial asume la dirección técnica de comercialización, esto es, la gerencia comercial del Establecimiento Turístico. El resto de áreas de la gerencia del establecimiento permanecen en manos del titular de la Explotación, razón por la cual, al no controlar todas las vertientes de la operación turística, el Grupo no ofrece la marca Cordial a los establecimientos contratados bajo esta modalidad. Bajo este modelo contractual se han incorporado cuatro establecimientos de Gran Canaria, el Hotel Riviera Vista de Playa del Cura (94 unidades alojativas), los Apartamentos Montecarlo en Puerto Rico (34 unidades), las Villas de Tauro (7 viviendas vacacionales) y los apartamentos Montemayor en Playa del inglés (27 unidades).

Fuera del territorio español, concretamente en el Caribe, este grupo posee un contrato de gestión comercial internacional con el Antiguo Hotel Europa, de 52 habitaciones, en la zona colonial de Santo Domingo, capital de República Dominicana.

\section{La Sostenibilidad como eje principal de su estrategia corporativa}

Otra de las bases de la política empresarial de la marca Be Cordial es su política de sostenibilidad ya que consideran prioritario su compromiso con el Archipiélago canario en general y con los países con los que operan en particular, así como con la comunidad local en el entorno de sus establecimientos. Así, su política de sostenibilidad está enfocada a sus clientes externos a quien tratan de fidelizar y orientar hacia sus políticas de reciclaje y ahorro energético y hacia sus empleados o clientes internos con quien se reúnen periódicamente para considerar sus opiniones y necesidades en sus puestos de trabajo.

En efecto, la actividad turística provoca un gran impacto tanto positivo como negativo en el entorno en el que opera (Tsai y otros 2010), lo que obliga a los empresarios del sector a adecuarse cada vez más a los principios de sostenibilidad, con la finalidad de aumentar la posibilidad de éxito de sus empresas (Rodríguez \& Armas Cruz 2007). Esto se traduce, por un lado, en una creciente preocupación de los establecimientos hoteleros por el entorno en el que desarrollan su actividad, lo que les lleva a esforzarse en cumplir con los más altos estándares de calidad medioambiental y, por otro lado, en la consolidación de una conciencia de responsabilidad social que les lleva a participar en la vida de los municipios y localidades en los que están presentes, a través de distintas iniciativas deportivas, culturales y de comunicación.

Concretamente, este grupo empresarial debe estar especialmente orgulloso de los logros obtenidos por el Hotel Cordial Mogán Playa y los Apartamentos Cordial Mogán Valle, los cuales han visto distinguido su compromiso social y medioambiental con el Galardón de Oro otorgado por el Sistema de Sostenibilidad Travelife ${ }^{2}$. En tal sentido, que un establecimiento hotelero sea reconocido por su compromiso con la sostenibilidad es una tarea ardua ya que

\footnotetext{
${ }^{2}$ El Sistema de Sostenibilidad de Travelife es una solución completa para las empresas turísticas que reconocen la importancia y las ventajas que reporta hacerse más sostenible. Proporciona todos los recursos necesarios para determinar los niveles actuales de rendimiento y facilitar las mejoras, a la vez que ofrece reconocimiento y recompensa por las buenas prácticas en áreas tales como la gestión ambiental, el empleo y las relaciones con la comunidad. Este sistema está apoyado y promocionado por las principales asociaciones profesionales turísticas y los mayores turoperadores europeos, que colaboraron para desarrollar los criterios en los que se basa Travelife. Esto se consiguió mediante un proceso de consulta a las múltiples partes interesadas, como los hoteleros, los institutos de investigación, los expertos en sostenibilidad y las ONG. Travelife fue co-fundada por la Iniciativa de Eco-Innovación de la Unión Europea.
} 
muchas iniciativas y procesos se producen sin la participación de los clientes y no son claramente observables. Así, Travelife es una herramienta que permite a los hoteleros comunicar sus logros en sostenibilidad y, por tanto, da a conocer mejor a los turoperadores las medidas medioambientales y de apoyo a los empleados internos y a la comunidad local que adoptan los hoteles a los cuales éstos envían a sus clientes, y a sus clientes directos les da motivos para desear alojarse en dichos establecimientos.

Por consiguiente, conseguir un premio Travelife año tras año requiere un óptimo resultado en la auditoría de esta compañía, pues supone la visita de un auditor profesional de Travelife a los hoteles del grupo quien realizará una evaluación analizando en profundidad las facturas de energía y sus comparativas con años anteriores y entrevistará al personal sobre las políticas de compras y de sostenibilidad que se desarrollan en la cadena. Además, el cuestionario del auditor incluye cuestiones como el apoyo a la comunidad local e inspeccionará la propiedad exhaustivamente para evaluar la gestión ambiental. Concretamente, Travelife otorga tres niveles de premios posibles: (1) Bronce que reconoce a aquellas empresas que tienen políticas y procedimientos que reducen activamente su impacto ambiental y que tratan a la gente de forma justa y respetuosa; (2) Plata para aquellas empresas que van más allá de las que cumplen con la certificación Bronce, buscando formas de proporcionar beneficios extra a la comunidad local y al medio ambiente; y, por último, (3) Oro, otorgado a las empresas que demuestran un alto compromiso con la sostenibilidad y animan a otras partes del sistema a participar (ej., proveedores, clientes, instituciones...) y buscan constantemente nuevas oportunidades de mejora, además de comunicar sus avances activamente a los demás.

La apuesta medioambiental de este grupo empresarial está presente en todos y cada uno de los procesos de los hoteles que gestiona. Así, desde el punto de vista de la sostenibilidad medioambiental, en Cordial son conscientes de la necesidad de respetar y proteger el medio ambiente, así como de la incidencia de sus actividades sobre él. Esta política medioambiental se ha concretado en los últimos años, entre muchas otras medidas, en: (a) utilizar medios biológicos para combatir las plagas en sus jardines, renunciando a productos químicos más agresivos con el ecosistema; (b) reducir la producción de residuos y el reciclado posterior de los mismos; (c) utilizar la energía solar y la energía residual del aire acondicionado para el calentamiento de las piscinas y, (d) climatizar las piscinas y calentar Agua Caliente Sanitaria con calderas de Biomasa (Pellet) que tienen un balance neutro de $\mathrm{CO}^{2}$, al cerrar el ciclo de carbono que comenzaron las plantas en su crecimiento. Así, las emisiones de la biomasa no son contaminantes, ya que su composición es básicamente el $\mathrm{CO}^{2}$ captado por la planta origen de la biomasa y el vapor de agua.

Por lo que a sostenibilidad social se refiere, para el grupo Cordial es una prioridad influir positivamente en la comunidad local, y es algo que les caracteriza particularmente. Esto se ha concretado en acciones como la contratación preferente de empleados locales. Así mismo han desarrollado una política de inversión en el patrimonio histórico y cultural de la zona de Mogán, municipio en el que se asienta su establecimiento más emblemático, el Hotel Cordial Mogán Playa, destacando la recuperación de la necrópolis aborigen de Las Crucecitas y las donaciones aportadas para distintos proyectos sociales del citado municipio de Mogán.

\section{Epílogo}

A medio y largo plazo el Grupo Cordial pretende continuar en la línea de crecimiento de una forma ordenada, responsable y sólida, sobre la base del modelo de contratos de gestión tanto en las Islas Canarias como en la región Caribe (principalmente República Dominicana y Cuba) 
y África Occidental (tiene muy avanzadas oportunidades en Gambia).

\section{Referencias}

Rodríguez, F.J. \& Armas Cruz, Y. (2007). Relation between social-environmental responsibility and performance in hotel firms. International Journal of Hospitality Management, 26, 824-839.

Sorensen, J.B. (2002). The Strength of Corporate Culture and the Reliability of Firm Performance. Administrative Science Quarterly, March, 70-91.
Tsai, W., Hsu, J., Chen, C., Lin, W. \& Chen, S. (2010). An integrated approach for selecting corporate social responsibility programs and costs evaluation in the international tourist hotel, International Journal of Hospitality Management, 29, 385-396.

Para el desarrollo de este caso ha sido entrevistado: Don Nicolás Villalobos Mestres (Director General del Grupo be Cordial) 